\title{
Experimental investigations into the mechanical performance of glulam dowel-type connections with either bolts or screws as fasteners
}

\author{
Zheng $\mathrm{Li}^{1,2}$, Wei Feng ${ }^{1}$, Jiajia Ou ${ }^{3}$, Feng Liang ${ }^{1}$ and Minjuan $\mathrm{He}^{1,2^{*}}$
}

\begin{abstract}
Dowel-type connections are the most common connections in glulam structures. Bolts are often used as fasteners for dowel-type connections. However, the clearance between the bolts and the pre-drilled bolt holes leads to low rotational stiffness and insufficient moment-resisting capacity. To achieve better mechanical performance, screws can be used as alternative fasteners for dowel-type connections. In this paper, monotonic and cyclic loading tests were conducted on glulam dowel-type connections with either bolts or screws as fasteners. The failure modes, momentresisting capacity, ductility ratio, stiffness degradation, and equivalent viscous damping ratio of the specimens were analyzed and reported. Results showed that compared with traditional bolted connections, the screwed connections had larger moment-resisting capacity and better ductility. The hysteretic loops of the screwed connections were plumper, and the pinching effect was gentler compared to those of traditional bolted connections.
\end{abstract}

Keywords: Glulam, Dowel-type connections, Screwed connections, Bolted connections, Mechanical performance

\section{Introduction}

Dowel-type connections are the most commonly used connections in glulam structures. The mechanical performance of dowel-type connections plays a significant role for the load-resisting performance of the structure. Usually, nails, bolts, screws, or tubes can be used as the fasteners for dowel-type connections. However, the fabrication techniques and behaviors of these connections differ a lot. Bolts are often used as fasteners in doweltype connections. For traditional bolted connections, the bolts usually go through the pre-drilled holes in both the glulam and the slotted-in steel plate to make these two components connected. Relative research shows a few shortcomings for traditional bolted connections, such

\footnotetext{
${ }^{*}$ Correspondence: hemj@tongji.edu.cn

${ }^{1}$ Department of Structural Engineering, Tongji University,

Shanghai 200092, People's Republic of China

Full list of author information is available at the end of the article
}

as low rotational stiffness, insufficient moment-resisting capacity, and unpredictable brittle failure, which result in unfavorable lateral load-resisting performance for the glulam structures [1-5]. Therefore, some reinforcing methods were proposed in order to improve the mechanical performance of the bolted connections. Based on the idea of reinforcing the glulam in the perpendicular-tograin direction, Blass and Bejtka [6], Lam et al. [7], and Gehloff et al. [8] investigated the performance of self-tapping screws (STS)-reinforced bolted connections with a series of experiments, and results showed the STS could effectively mitigate the crack propagation and improve the ductility of the connections. Meanwhile, both the moment-resisting and the energy dissipation capacities were increased. With the similar idea, plain round rods (PRP), locally cross-laminated members and fiberreinforced polymer (FRP) were also used to reinforce the glulam in the perpendicular-to-grain direction, and experimental together with numerical results showed 
obvious enhancement on the mechanical performance of bolted connections [9-11]. On the other hand, glued plywood plates, weft knitted textiles, and steel inserts were used to reinforce the wood region around the dowel holes, and the results showed the load-resisting capacity and the ductility of the connections were improved [12-14]. In addition, wedge angles were used to reinforce a kind of hybrid timber beam-to-tubular steel column bolted connection by Karagiannis et al. [15]. The pretension technique and energy dissipation devices were introduced into the bolted connection to provide a recentering force for the glulam connections by $\mathrm{Li}$ et al. [16].

Except for the development of traditional bolted connections, research was also conducted to investigate the mechanical performance of some novel dowel-type connections. Steel tubes were used as fasteners and densified veneer wood was glued to the glulam to prevent wood splitting by Leijten et al. [17]. A kind of dowel-type connection using slotted-in compressed wooden plate and compressed wooden dowels instead of the steel plate and bolts for traditional bolted connections was investigated by Jung et al. [18, 19]. Araki et al. [20] proposed a new connection using hollow steel tubes as fasteners. The tubes were inserted through the slotted-in steel plate and were fixed to the wood member with resin injection. A kind of pre-stressed tube bolted connection, in which the pre-stressed bolts went through the steel tubes to connect the slotted-in steel plate and the glulam beam more effectively was investigated by $\mathrm{He}$ et al. [21]. Research results showed these connections could provide better performance compared with traditional bolted connections, but problems might exist such as the complex assembling process of the tubes and the steel dowels.

Recently, the fastener of coach screws was used in the connections of timber-concrete or timber-steel composite members, and research was carried out to investigate the mechanical performance of these kinds of connections [22-24]. Relative research results showed that the screwed connections might overcome the disadvantage of low rotational stiffness for traditional bolted connections because of the tight contact between the screws and the screw holes. The factors influencing the performance of coach screws, such as the diameter of the screws and the wood species, were studied by Smith et al. [25]. The load-resisting capacity and the load-slip characteristics of the coach screwed connections in the timber-concrete composites were studied by Symons et al. [26], Sebastian et al. [27], Jiang et al. [28], and Du et al. [29]. The mechanical performance of both lap laminated veneer lumber (LVL)-steel composite connections and crosslaminated timber (CLT)-steel composite connections with coach screws was investigated by Hassanieh et al.
[30, 31]. Furthermore, hysteretic performance of the connections with both bolts and screws as fasteners in CLT shear walls was investigated by Li et al. [32] and Sun et al. [33].

A kind of dowel-type connection using coach screws as fasteners was investigated in this paper. The connection consisted of the glulam beam, a $\pi$-shaped steel, and the coach screws. The coach screws were drilled into the glulam through holes in the clamps of the $\pi$-shaped steel. It could avoid the clearance between the fasteners and the pre-drilled holes, and was also a relatively efficient way of assembling. To investigate the mechanical performance of this kind of screwed connection and compare its behavior with traditional bolted connections, monotonic and cyclic loading tests were conducted. The failure modes, moment-resisting capacity, ductility ratio, stiffness degradation, and equivalent viscous damping ratio were analyzed and reported. The mechanical performance of the bolted connection and the screwed connection was compared.

\section{Materials and test methods}

Two kinds of dowel-type connections with different fasteners were designed. One was the bolted connection (BC) and the other was the coach screwed connection (CSC), as shown in Figs. 1, 2. The BC specimen is composed of a T-shaped slotted-in steel and the glulam beam which is connected with the web of the T-shaped slottedin steel with bolts. The CSC specimen is composed of a $\pi$-shaped steel and the glulam beam which is connected with the clamps of the $\pi$-shaped steel with coach screws. The geometric dimension of the glulam beams was the same for both the BC specimens and the CSC specimens. Therefore, the influence of different fasteners can be studied by analyzing these specimens. Both the $\mathrm{BC}$ specimens and the CSC specimens were divided into 2 groups. The first group had two replicates (named $\mathrm{BC} 1, \mathrm{BC} 2$ or CSC1, CSC2, respectively) and was tested under monotonic loading protocol. The second group had one replicate (named $\mathrm{BC} 3$ or $\mathrm{CSC} 3$, respectively) and was tested under cyclic loading protocol.

\section{Materials}

The glulam beams were fabricated by No. 2 stress-graded Douglas fir dimensional lumber. The air-dry density of the dimension lumber was $509 \mathrm{~kg} / \mathrm{m}^{3}$ and the moisture content was $10.57 \%$ on average. The parallel-to-grain modulus of elasticity, parallel-to-grain compressive strength, and perpendicular-to-grain compressive strength of the dimension lumber were $11,742 \mathrm{MPa}, 46.00 \mathrm{MPa}$, and $6.69 \mathrm{MPa}$, respectively. Both the T-shaped steel and the $\pi$-shaped steel were made of mild carbon structural steel Q235B with a nominal yielding strength of 


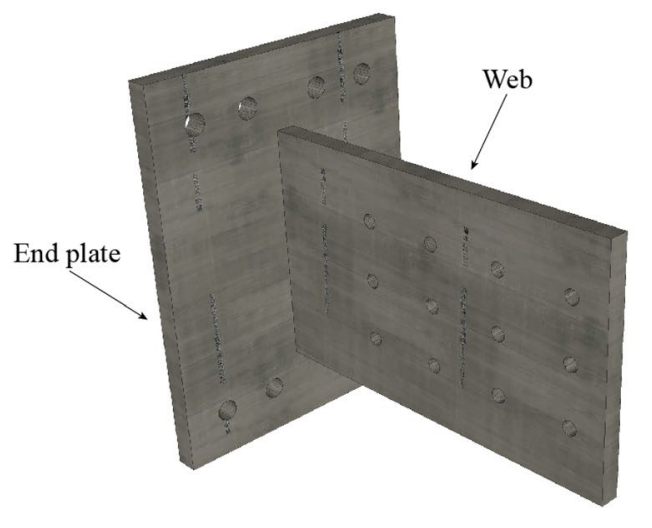

a T-shaped slotted-in steel

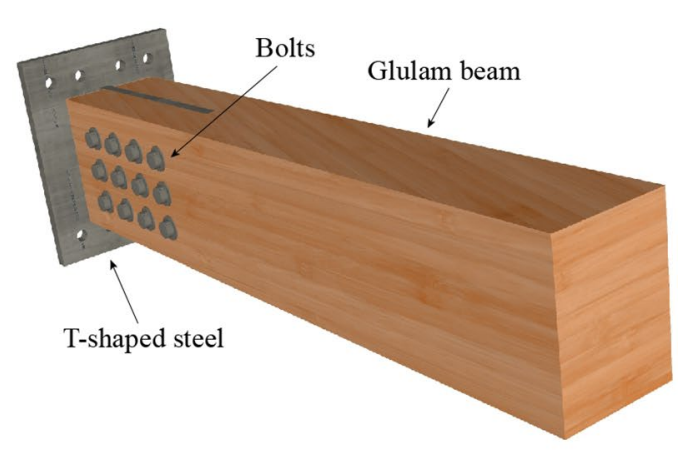

b The BC specimen

Fig. 1 Configuration of the bolted connection. a T-shaped slotted-in steel. b The BC specimen

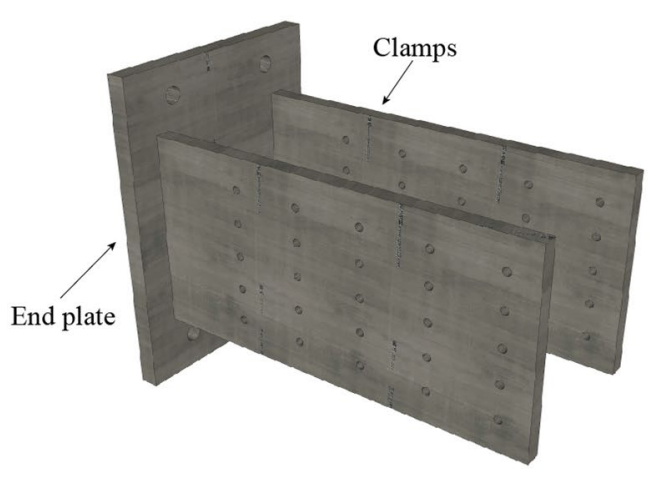

a $\pi$-shaped steel

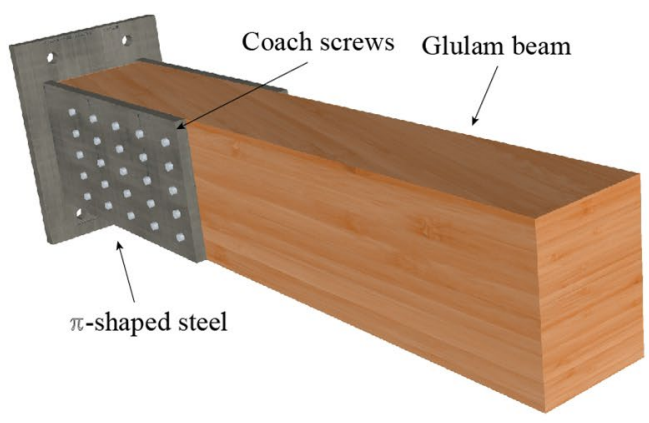

b The CSC specimen

Fig. 2 Configuration of the coach screwed connection. a $\pi$-shaped steel. $\mathbf{b}$ The CSC specimen

$235 \mathrm{MPa}$ conforming to Chinese Standard for Design of Steel Structures [34]. The bolts were 8.8 grade bolts with a length of $180 \mathrm{~mm}$ (the length of the thread part was $40 \mathrm{~mm}$ ), and the outer diameter of the bolts was $12 \mathrm{~mm}$. The coach screws were imported hexagonal coach screws (08A grade) made by the Rothoblaas company with a length of $80 \mathrm{~mm}$ (the length of the thread part was $64 \mathrm{~mm}$ ), and the outer diameter of the screws was $8 \mathrm{~mm}$. Particularly, the characteristic yielding moment-resisting capacity and the tensile-resisting capacity of the screws were $1.69 \times 10^{-2} \mathrm{kN} \cdot \mathrm{m}$ and $15.7 \mathrm{kN}$, respectively.

\section{Specimen design}

The configurations of the $\mathrm{BC}$ specimens and the CSC specimens are illustrated in Fig. 3. The specimens are full scale. The glulam beams were $200 \times 150 \mathrm{~mm}$ in cross-section and $1000 \mathrm{~mm}$ in length. The cross section size of the beam was chosen based on a common size in glulam structures. Both the $\mathrm{BC}$ specimens and the CSC specimens were designed according to Structural Timber Design to Eurocode 5 [35], to have the same design moment-resisting capacity as the glulam beam. The connection details, such as the spacing, end, and edge-distance of bolts or coach screws, also met the requirements of literature [35]. For the $\mathrm{BC}$ specimens, the diameter of the pre-drilled holes was $13.5 \mathrm{~mm}$ in the glulam and $12.5 \mathrm{~mm}$ in the web of the T-shaped steel, respectively. The oversized pre-drilled holes in the glulam made it convenient to assemble different structural components with bolts, because the rough inner surface of the predrilled holes in the glulam and the alignment error of the pre-drilled holes might affect the assembling if small size of pre-drilled holes was used. However, the clearance between the bolts and the pre-drilled holes in the glulam makes the bolted connection rotate with low stiffness in the initial stage. Pre-drilled holes in the end plate of the 


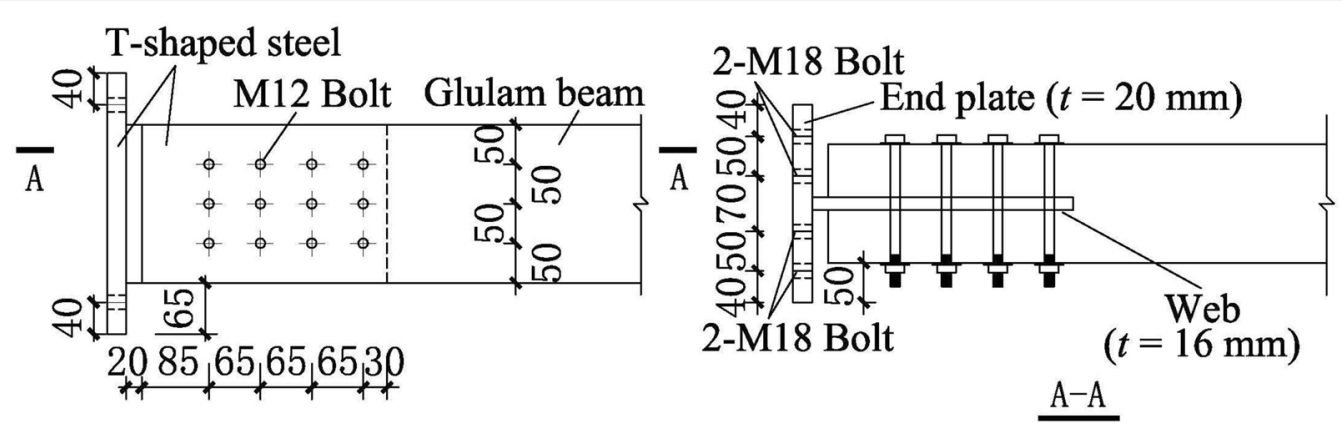

a The $\mathrm{BC}$ specimens
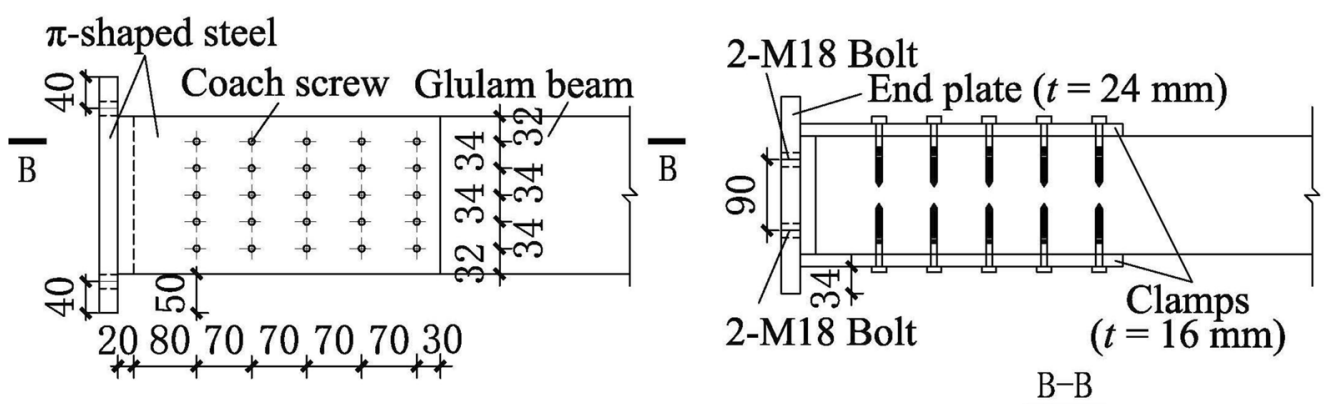

b The CSC specimens

Fig. 3 Configurations of the specimens. a The BC specimens. b The CSC specimens

T-shaped steel were $18.5 \mathrm{~mm}$ in diameter because high strength bolts with $18 \mathrm{~mm}$ in diameter were used to connect the $\mathrm{BC}$ specimens with the rigid foundation beam. The thicknesses of the end plate and the web were 20 and $16 \mathrm{~mm}$, respectively. In addition, there was a gap of $20 \mathrm{~mm}$ between the end plate and the bottom of the glulam beam, which was designed to avoid the compaction between them.

For the CSC specimens, the diameter of the pre-drilled holes was $8.5 \mathrm{~mm}$ in the clamps of the $\pi$-shaped steel. There are also pre-drilled holes in the glulam beam, which were about $5.5 \mathrm{~mm}$ in the diameter. However, holes in the glulam did not need locating accurately or cutting through the glulam compared to those of the bolted connections, and the size of the pre-drilled holes was smaller than that of the coach screws. This is because the thread of the coach screws made themself able to be drilled into the glulam, and these pre-drilled holes were only for the ease of drilling. Therefore, oversized pre-drilled holes were not necessary and it would not affect the assembling if the drilling precision was not that high. Furthermore, because there is almost no clearance between the screws and the screw holes, this kind of connection could effectively resist the applied load with high rotational stiffness even in the initial stage. Pre-drilled holes in the end plate of the $\pi$-shaped steel were the same as the BC specimens and the high strength bolts with $18 \mathrm{~mm}$ in diameter were also used to connect the specimens with the rigid foundation beam. The thicknesses of the end plate and the clamps were 24 and $16 \mathrm{~mm}$, respectively. The designed gap between the end plate and the glulam beam was $20 \mathrm{~mm}$, which was the same as the $\mathrm{BC}$ specimens.

\section{Test methods}

As illustrated in Fig. 4, both the $\mathrm{BC}$ specimens and the CSC specimens were rotated by $90^{\circ}$ to be loaded availably with the specific loading equipment. The specimens were fixed on the rigid foundation beam using high strength bolts. The lateral load was applied through the electrohydraulic servo loading system with the actuator. The load range is $\pm 300 \mathrm{kN}$ and the displacement range is $\pm 250 \mathrm{~mm}$, respectively. The rotation angles of the glulam beam and the T-shaped steel (or $\pi$-shaped steel) were calculated using the horizontal displacements collected by the linear voltage displacement transducers (LVDTs). LVDT 1 was used to record the horizontal displacement of the actuator. LVDT 3, 5 were used to calculated the rotation of the glulam beam, and LVDT 2, 4 were used 


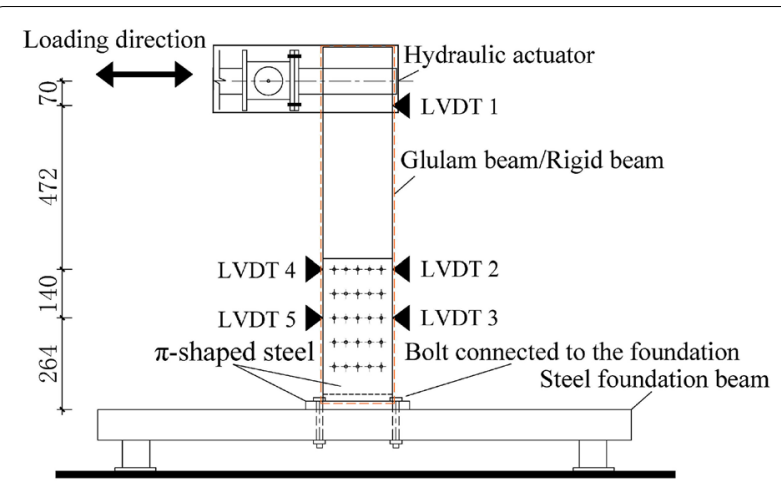

Fig. 4 Test set-up and measurement arrangement

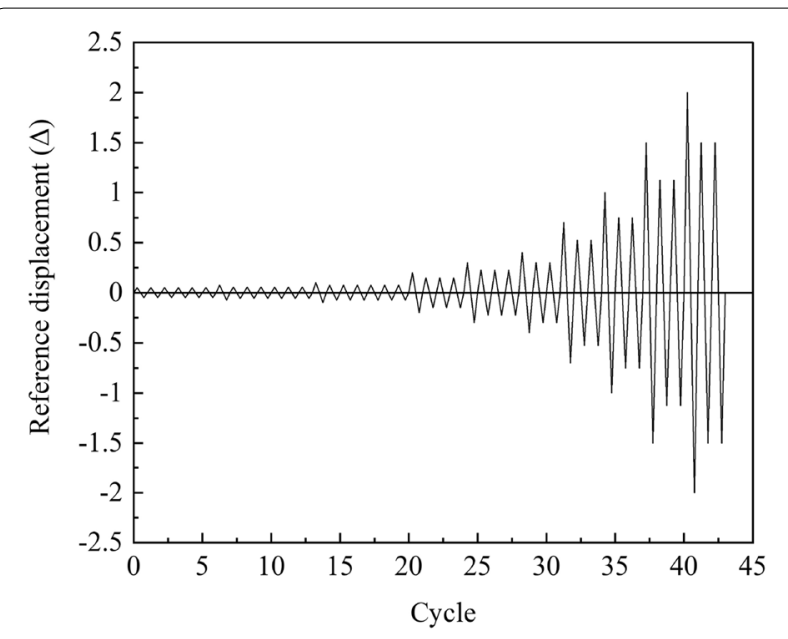

Fig. 5 CUREE loading protocol to calculated the rotation of the steel clamps or slotted-in web.

For the monotonic loading test, the displacement-controlled loading method was used with the loading rate of $5 \mathrm{~mm} / \mathrm{min}$ based on ASTM D1761-12 [36]. The test would be stopped either when the applied load falls to $80 \%$ of the ultimate load or when the tested specimen severely damaged.

For the cyclic loading test, the CUREE displacementcontrolled reciprocating loading method was used with the loading rate of $60 \mathrm{~mm} / \mathrm{min}$ based on ASTM E212611 [37]. The loading regime is illustrated in Fig. 5 and the reference displacement $\Delta$ is determined as $60 \%$ of the ultimate loading displacement under the monotonic loading test. At first, 6 loading cycles were performed with equal displacement amplitude of $0.05 \Delta$. Then, the subsequent loading included the primary cycles and the trailing cycles, wherein the displacement amplitude of the primary cycle successively increased from $0.075 \Delta$ to $2.0 \Delta$ (i.e., $0.075 \Delta, 0.1 \Delta, 0.2 \Delta, 0.3 \Delta, 0.4 \Delta, 0.7 \Delta, 1.0 \Delta, 1.5 \Delta$, $2.0 \Delta$, respectively). After each primary cycle, a series of trailing cycles were implemented as $75 \%$ of the primary cycle's amplitude. Especially, there were 6 trailing cycles after the primary cycles of $0.075 \Delta$ and $0.1 \Delta, 3$ trailing cycles after the primary cycles of $0.2 \Delta$ and $0.3 \Delta$, and 2 trailing cycles after the primary cycles of $0.4 \Delta, 0.7 \Delta$, $1.0 \Delta, 1.5 \Delta$, and $2.0 \Delta$.

\section{Results and discussion Monotonic loading test}

Specimen BC1, BC2, CSC1, and CSC2 were tested under monotonic loading protocol. The moment-rotation curves are depicted in Fig. 6 through the data recorded by the loading equipment and the LVDTs.

For the BC specimens, small sound of cracking was heard and the relative slip between the web of the

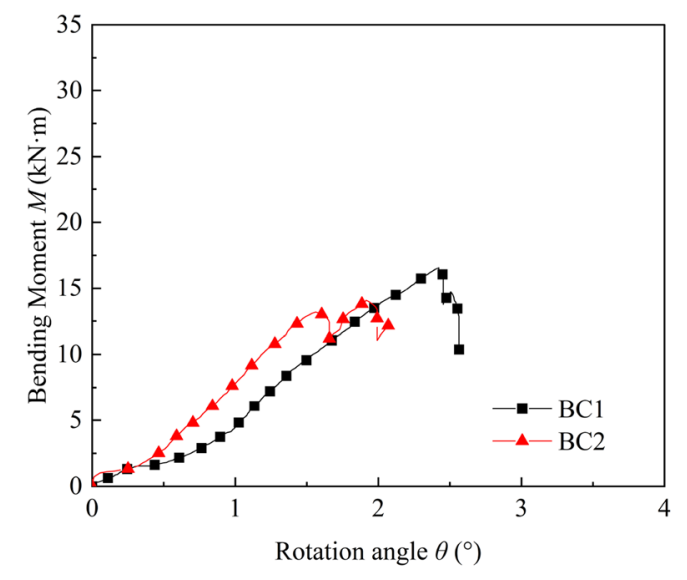

a The $\mathrm{BC}$ specimens

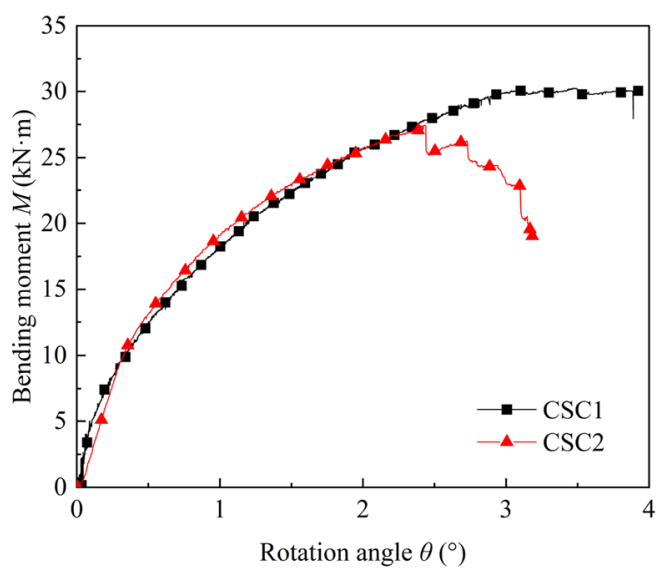

b The CSC specimens

Fig. 6 Moment-rotation curves under monotonic loading protocol. a The BC specimens. b The CSC specimens 
T-shaped slotted-in steel and the glulam beam was observed in the initial loading stage. Because of the existed clearance between the bolts and the bolt holes in the glulam, the moment-rotation curves showed relatively low stiffness in the initial stage. As the contact between the bolts and the bolt holes was complicated, the range of this low stiffness segment was unpredictable. Previous experimental research on bolted beamto-column connections $[9,21,38]$ had shown that this stage of low stiffness ranged from $0^{\circ}$ to $0.7^{\circ}$ on average. From this point, the test results were more reliable. With the increase of the applied load, the rotation of the glulam beam became obvious and the slip between the web and the beam became larger. Because the bolts had already contacted with the bolt holes tightly, the curves presented a relatively high stiffness until obvious plasticity occurred in the specimens. The first crack appeared either on the tension or the compression side of the glulam beam. Then, the cracks slowly spread to the upper part of the beam and occurred on both the tension and the compression sides. Large sound of cracking could be heard. At last, as shown in Fig. 7a, splitting cracks on the tension side developed rapidly and the load applied to the specimens descended suddenly, so the loading was terminated. As depicted in Fig. 6a, the plastic stage of the BC specimens was not obvious and the stiffness in the final segment of the curves was relatively high before failure, which conformed to the previous research of $\mathrm{Yu}$ [38]. It could be explained by that the diameter of bolts was relatively big while the distance from the bolts to the end of the glulam beam was small, thus resulting in large transverse tensile stress and brittle splitting failure of the glu$\mathrm{lam}$. That is also one of the reasons why traditional bolted connections have a relatively low moment-resisting capacity and poor ductility. It was noticed that specimen

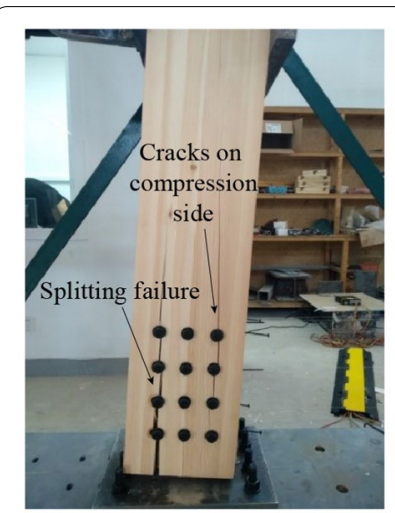

a Failure of the glulam

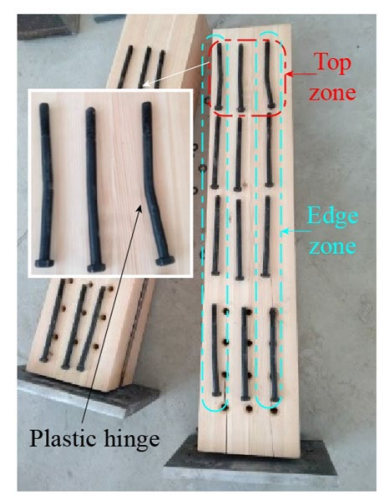

b Deformation of bolts
Fig. 7 Failure modes of the BC specimens. a Failure of the glulam. $\mathbf{b}$ Deformation of bolts
$\mathrm{BC} 2$ had a lower moment-resisting capacity and the latter part of the curve fluctuated obviously compared with specimen $\mathrm{BC} 1$. Through observation in the test, an initial defect of the wood knot was found on the path of a crack and accelerated the spread of the crack, making specimen $\mathrm{BC} 2$ behaved worse than specimen $\mathrm{BC} 1$. After the experiments, the specimens were disassembled to further study the deformation modes of the bolts, as shown in Fig. $7 \mathrm{~b}$. Bolts in the top edge zones presented the most severe deformation which conformed to the "one-hinge" yielding mode. To explain the mechanism, the bolts were thought to resist the shear force and the bending moment in the same time caused by the lateral load, and the rotation center could be assumed to be the geometric center of the bolts group. Therefore, the magnitude of the force caused by the bending moment of one bolt was linear to the distance from the rotation center to this bolt, and the direction of this force was perpendicular to the line going through the rotation center and the bolt. On the other hand, the force caused by shear was assumed to be distributed averagely to each bolt and pointed parallel to the direction of the shear force. Finally, the resultant force was obtained by adding the force caused by the bending moment and the force caused by shear according to the rule of vectors, which could be concluded that the top edge bolts suffered the biggest force. Therefore, the deformation of the top edge bolts was the most obvious.

For the CSC specimens, the initial stiffness was much higher than that of the $\mathrm{BC}$ specimens without the initial low stiffness stage, as shown in Fig. 6b. The initial linear segment of the moment-rotation curves indicated that the specimens were under elastic stage. Contrary to the $\mathrm{BC}$ specimens, because the coach screws were drilled into the glulam beam, which made no initial clearance between the screws and the screw holes, the screws contacted tightly with the wood fibers and worked effectively as soon as the external force applied to the specimens. With the increase of the applied load, relative slip was observed between the clamps of the $\pi$-shaped steel and the glulam beam. The glulam beam rotated obviously. The sound of cracking could be heard but cracks were not able to be observed because of the covering of the clamps. The slope of the curves became smaller, meaning that plasticity developed in the specimens. The applied load continued to increase and the cracks became visible, which extended from the area under the clamps to the upper part of the glulam beam. Then, more cracks developed and the screws in the top edge zone were sheared. The applied load could hardly rise any more. Finally, the splitting crack on the tension side of the glulam beam propagated rapidly and the applied load descended suddenly, so the loading was terminated. The relative slip between the clamps and the glulam beam was as large as 
$20 \mathrm{~mm}$. In contrast with the $\mathrm{BC}$ specimens, the momentrotation curves of specimen CSC1 and specimen CSC2 were similar due to the fact that there was no unpredictable initial low stiffness stage or significant initial defect in the CSC specimens. The CSC specimens presented an obvious plastic segment in the curves, which meant the plasticity developed more effectively compared with the $\mathrm{BC}$ specimens. This could be explained by that the relatively small diameter of screws relieved the large transverse tensile stress for the bolted connections, so the ductile embedment failure together with the brittle splitting failure happened during loading, as shown in Fig. 8a. Therefore, the failure of CSC specimens was more ductile. The shear failure, "one-hinge" and "two-hinge" yielding failures were observed in the top, bottom and edge zones, as illustrated in Fig. $8 \mathrm{~b}$. The different degrees of damage in screws could be explained with the same mechanism as the $\mathrm{BC}$ specimens, which was the addition of the force caused by the bending moment and the force caused by shear.

Mechanical properties, such as the initial stiffness $\left(K_{\mathrm{e}}\right)$, the yielding moment $\left(M_{\mathrm{y}}\right)$, and the ductility ratio $(\mu)$, can

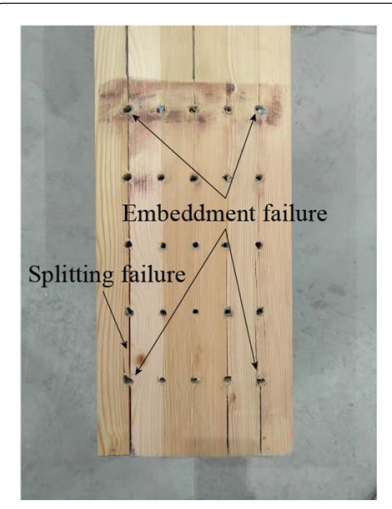

a Failure of the glulam

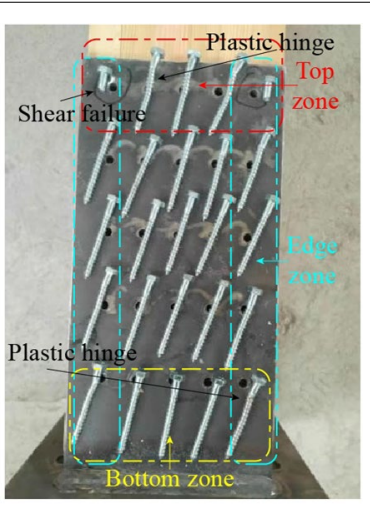

b Deformation of screws
Fig. 8 Failure modes of the CSC specimens. a Failure of the glulam. $\mathbf{b}$ Deformation of screws be calculated based on the Y\&K method [39]. The results are listed in Table 1 , in which $\theta_{\mathrm{y}}$ is the corresponding rotation angle of $M_{\mathrm{y}} ; M_{\mathrm{p}}$ is the maximum moment and $\theta_{\mathrm{p}}$ is the corresponding rotation angle; $M_{\mathrm{f}}$ is the failure moment and $\theta_{\mathrm{f}}$ is the corresponding rotation angle; and $\mu$ is equal to $\theta_{\mathrm{f}}$ divided by $\theta_{\mathrm{y}}$. Because the initial stage of the $\mathrm{BC}$ specimens was unpredictable and the stiffness was quite low, if the initial stage was considered when applying the Y\&K method, some problems might happen. For example, the stiffness in the plastic stage might be much bigger than that of the elastic stage, and the yielding moment would be also underestimated, which were not reasonable to describe the behavior of the $\mathrm{BC}$ specimens. Therefore, the initial stage of low stiffness was not considered when using the Y\&K method.

The initial stiffness of the CSC specimens was 133\% higher than that of the $\mathrm{BC}$ specimens on average, which was mainly improved by the tight contact between the screws and the screw holes. The yielding moment of the CSC specimens was $22 \%$ higher that of the BC specimens. The yielding rotation angle of the CSC specimens was $59 \%$ lower than that of the BC specimens, and this was because the $\mathrm{BC}$ specimens had to experience the initial stage of low stiffness until the yielding point. The ultimate moment and the failure moment of the CSC specimens were $93 \%$ and $87 \%$ higher than those of the BC specimens, respectively. The ultimate rotation angle and the failure rotation angle of the CSC specimens were $39 \%$ and $54 \%$ higher than those of the BC specimens, respectively. It showed that the performance after yielding of the CSC specimens was better than that of the BC specimens. Although the $\mathrm{BC}$ specimens and the CSC specimens had the similar yielding moments, the ultimate and the failure moments of the CSC specimens were much higher, which could serve as a safety margin. The initial stage of low stiffness for the $\mathrm{BC}$ specimens made it a higher yielding rotation angle, but after yielding the $\mathrm{BC}$ specimens failed quickly and could hardly develop the plasticity effectively, so the ultimate and the

Table 1 Mechanical properties calculated based on Y\&K method

\begin{tabular}{|c|c|c|c|c|c|c|c|c|}
\hline \multirow[t]{2}{*}{ Specimens } & \multirow{2}{*}{$\begin{array}{l}\text { Initial stiffness } \\
K_{\mathrm{e}}\left(\mathrm{kN} \cdot \mathrm{m} /{ }^{\circ}\right)\end{array}$} & \multicolumn{2}{|c|}{ Yielding point } & \multicolumn{2}{|c|}{ Maximum point } & \multicolumn{2}{|c|}{ Failure point } & \multirow{2}{*}{$\begin{array}{l}\text { Ductility ratio } \\
\mu=\theta_{\mathrm{f}} / \theta_{\mathrm{y}}\end{array}$} \\
\hline & & $M_{\mathrm{y}}(\mathrm{kN} \cdot \mathrm{m})$ & $\theta_{y}\left({ }^{\circ}\right)$ & $M_{\mathrm{p}}(\mathrm{kN} \cdot \mathrm{m})$ & $\theta_{p}\left({ }^{\circ}\right)$ & $M_{\mathrm{f}}(\mathrm{kN} \cdot \mathrm{m})$ & $\theta_{\mathrm{f}}\left({ }^{\circ}\right)$ & \\
\hline $\mathrm{BC} 1$ & 10.46 & 10.63 & 1.58 & 16.56 & 2.42 & 14.71 & 2.51 & 1.59 \\
\hline $\mathrm{BC2}$ & 9.72 & 13.18 & 1.56 & 13.18 & 1.56 & 14.06 & 1.91 & 1.22 \\
\hline Avg BC & 10.09 & 11.91 & 1.57 & 14.87 & 1.99 & 14.39 & 2.21 & 1.41 \\
\hline $\mathrm{CSC} 1$ & 21.45 & 14.40 & 0.66 & 30.12 & 3.10 & 29.90 & 3.89 & 5.92 \\
\hline $\mathrm{CSC} 2$ & 25.61 & 14.74 & 0.62 & 27.42 & 2.44 & 24.39 & 2.92 & 4.68 \\
\hline Avg CSC & 23.53 & 14.57 & 0.64 & 28.77 & 2.77 & 27.15 & 3.41 & 5.3 \\
\hline Improvement (\%) & 133 & 22 & -59 & 93 & 39 & 87 & 54 & 276 \\
\hline
\end{tabular}


failure rotation angles were smaller than those of the CSC specimens. For the same reason, ductility of the BC specimens was also worse than that of the CSC specimens. To describe the ductility performance exactly, the ductility ratio was used. Ductility ratio of 5.3 for the CSC specimens, which was greater than 4 , indicated the CSC specimens had a good ductile performance [40]. In contrast, ductility ratio of 1.41 meant it tended to be a brittle failure for the $\mathrm{BC}$ specimens. In general, the momentresisting capacity and the ductility of the coach screwed connections improved a lot compared with the bolted connections.

\section{Cyclic loading test}

Specimen BC3 and specimen CSC3 were tested under cyclic loading based on CUREE loading protocol. The hysteretic loops are depicted in Fig. 9. Under cyclic loading protocol, the specimens failed similarly to those under monotonic loading protocol, except that failure on both sides of the glulam was similar because either side of the specimens could be in tension or compression under cyclic loading protocol.

Compared with specimen BC3, the hysteretic loop of specimen CSC3 was plumper, and the pinching phenomenon was gentler. The total energy dissipation was calculated, equal to the area enclosed by the hysteretic loop. As illustrated in Fig. 10, the energy at each displacement amplitude included the energy dissipated both in the primary circle and the trailing cycles. Specimen BC3 failed in the primary cycle of $1.5 \Delta$ and the hysteretic curve was not complete for this cycle, so the total energy dissipated of $1.5 \Delta$ was unable to calculate. The hysteretic loops and the total energy dissipation indicated a better energy dissipation capacity of specimen CSC3. The skeleton curves also presented the characteristics of high initial stiffness

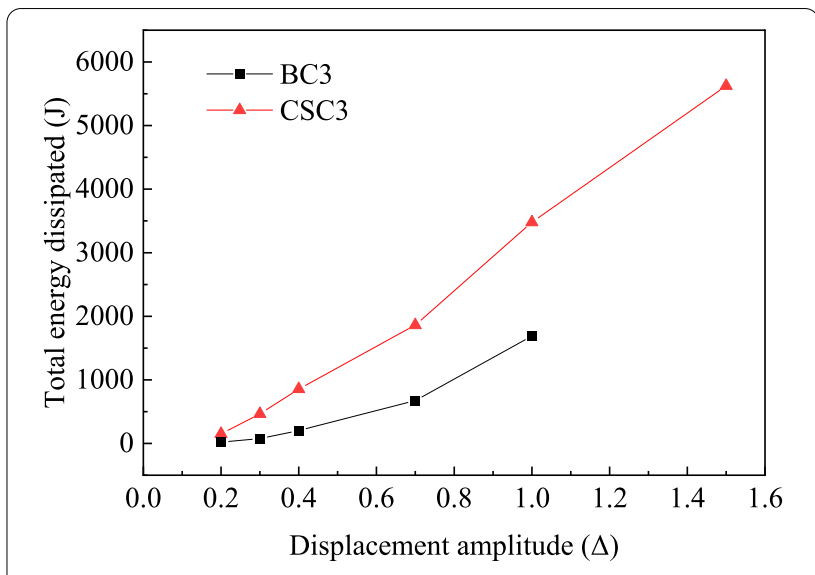

Fig. 10 Total energy dissipation

and good ductility of the CSC specimens, as those shown under monotonic loading protocol.

To further study the performance of the specimens under cyclic loading protocol, the stiffness degradation and the equivalent viscous damping ratio (EVDR for short) were analyzed. The secant stiffness $\left(K_{i}\right)$ of each primary cycle can be calculated using Eq. (1), where $+M_{i}$ and $-M_{i}$ are the positive and negative peak moment of the $i$-th primary cycle, respectively; $+\theta_{i}$ and $-\theta_{i}$ are the rotation angles corresponding to $+M_{i}$ and $-M_{i}$. The $\operatorname{EVDR}\left(\varepsilon_{\text {eq }}\right)$ can be calculated based on Eq. (2), where $E_{\mathrm{d}}$ is the dissipated energy in a primary cycle; $E_{\mathrm{p}}$ is the available potential energy in a primary cycle. The calculated results are illustrated in Fig. 11.

$$
K_{i}=\frac{\left|+M_{i}\right|+\left|-M_{i}\right|}{\left|+\theta_{i}\right|+\left|-\theta_{i}\right|}
$$

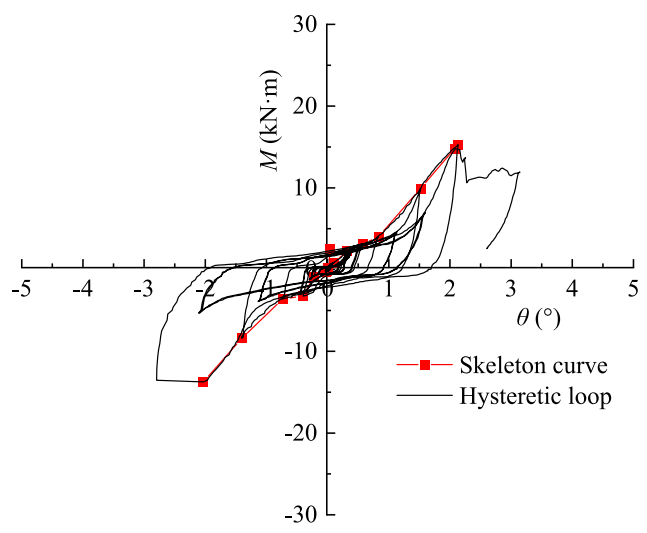

a Specimen $\mathrm{BC} 3$

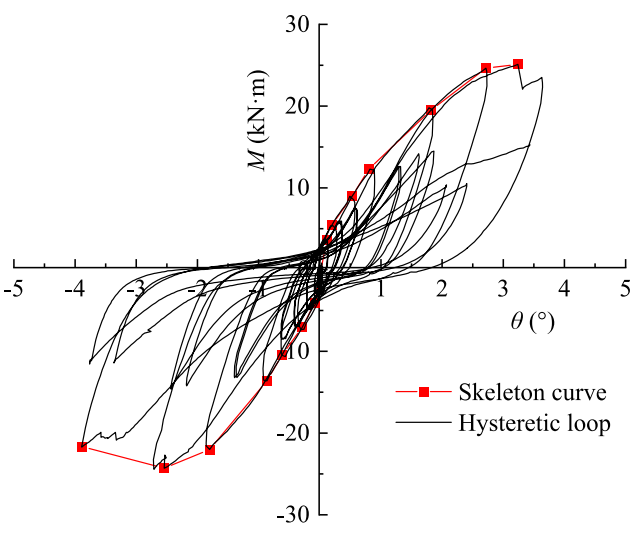

b Specimen CSC3

Fig. 9 Hysteretic loops. a Specimen BC3. b Specimen CSC3 


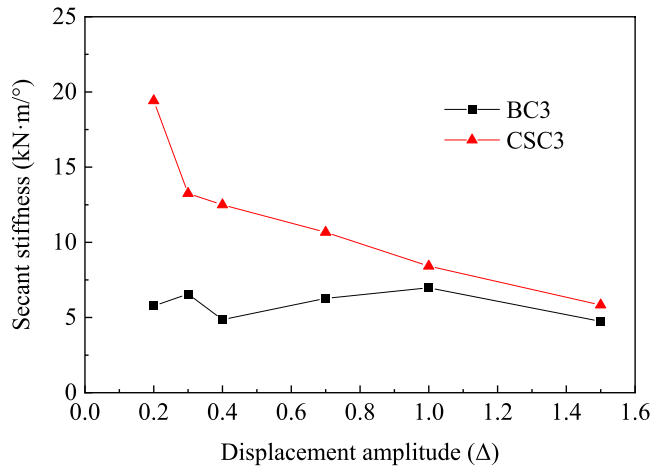

a Stiffness degradation

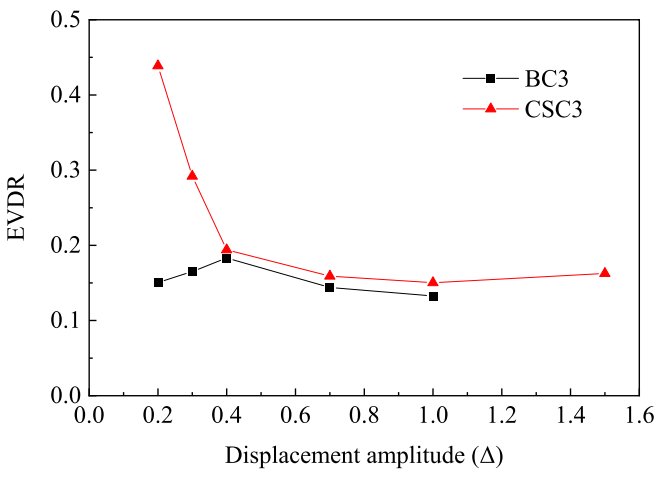

b EVDR

Fig. 11 Stiffness degradation and EVDR of the specimens. a Stiffness degradation. b EVDR

$$
\varepsilon_{\mathrm{eq}}=\frac{E_{\mathrm{d}}}{2 \pi E_{\mathrm{p}}}
$$

As can be observed in Fig. 11, the performance of stiffness degradation and EVDR of specimen CSC3 was better than those of specimen BC3.Specimen BC3 failed in the primary cycle of $1.5 \Delta$ and the hysteretic curve was not complete for this cycle, so the EVDR of $1.5 \Delta$ was unable to calculate.

From the displacement amplitude of $0.2-0.4 \Delta$, the rotation angle of specimen BC3 was relatively small but contained a large part of low stiffness. Therefore, the secant stiffnesses in this range were relatively low. After the displacement amplitude of $0.4 \Delta$, as the bolts and the bolt holes contacted more and more tightly, the secant stiffness began to increase until the displacement amplitude of $1.0 \Delta$. Then, large cracks were observed and propagated gradually, so the secant stiffness started to decrease, which indicated the damage accumulation in specimen $\mathrm{BC} 3$. On the other hand, the energy dissipation capacity that can be described by the EVDR mainly depends on the deformation of the bolts, the compression between the bolts and the bolt holes, and the friction among the bolts, the web of the T-shaped slotted-in steel, and the glulam beam. With the displacement amplitude increasing until $0.4 \Delta$, the contact among each component became more and more sufficient, while cracks did not occur in the specimen, so the energy dissipation capacity continued to increase. After the displacement amplitude of $0.4 \Delta$, cracks spread gradually in the specimen, which was not conducive to the compression between the bolts and the glulam beam. In addition, the effect of cyclic loading caused looseness between the glulam and the web, thus reducing the friction between them. Therefore, the capacity of energy dissipation kept decreasing.
For specimen CSC3, it showed a high secant stiffness and energy dissipation capacity in the initial loading stage, which could be explained by the tight contact among the screws, glulam beam and the clamps of the $\pi$-shaped steel. As the displacement amplitude increased in the following primary cycles, plasticity developed in the screws as well as in the wood fibers. Then, cracks appeared and propagated gradually. Therefore, the secant stiffness continued to decrease. Similar to specimen $\mathrm{BC} 3$, the energy dissipation capacity of specimen CSC3 depends on the deformation of the screws, the compression between the screws and the screw holes, and the friction among the screws, clamps and the glulam beam. With the increase of the displacement amplitude, plastic deformation and the appeared cracks made the contact insufficient, which also led to the failure of the screws and larger cracks in the final loading stage. The effect of cyclic loading also caused looseness between the glulam and the clamps. As a result, the secant stiffness and the EVDR kept decreasing. However, the secant stiffness and the EVDR were still larger than those of specimen BC3 under different displacement amplitudes.

\section{Conclusions}

A kind of dowel-type connection with hexagonal coach screws as fasteners was investigated. Monotonic and cyclic loading experiments were carried out to study the mechanical performance of this kind of connection and its load-resisting properties were further compared with traditional bolted connections. The failure modes, moment-resisting capacity, and hysteretic performance were obtained and compared. It can be concluded the following:

(1) Under monotonic loading protocol, the failure modes of the bolted connections were the splitting 
failure on the tension side of the glulam beam, and the "one-hinge" yield failure was observed in the top edge bolts. However, for the screwed connections, the failure modes of the glulam beam were the splitting failure on the tension side together with embedment failure of the screw holes. In addition, shear failure, "one-hinge" yielding failure and "two-hinge" yielding failure were observed in coach screws.

(2) The initial stiffness, yielding moment, ultimate moment, and ductility ratio of the screwed connections were respectively $133 \%, 22 \%, 93 \%$, and 276\% larger than those of the bolted connections. Especially, the screwed connections could overcome the disadvantages of low initial stiffness and low ductility existed in bolted connections. And the higher ultimate moment-resisting capacity could serve as the safety margin.

(3) The hysteretic loops of the screwed connection were plumper, and the pinching effect was gentler compared to those of the bolted connection. The energy dissipation capacity of the screwed connection was also better compared to the bolted connection.

It should also be noted that the sample size in this study is relatively limited. Therefore, the influence of material variabilities on the mechanical performance of the bolted connection and the screwed connection may not be fully considered. Further research is still needed to investigate the mechanical behavior of the screwed connection.

\footnotetext{
Abbreviations

$K_{\mathrm{e}}$ : Initial stiffness; $M_{\mathrm{y}}$ : Yielding moment; $\theta_{\mathrm{y}}$ : Corresponding rotation angle of $M_{\mathrm{y} i} M_{\mathrm{p}}$ : Maximum moment; $\theta_{\mathrm{p}}$ : Corresponding rotation angle of $M_{\mathrm{p}} ; M_{\mathrm{f}}$ : Failure moment; $\theta_{f}$ : Corresponding rotation angle of $M_{f} ; \mu$ : Ductility ratio, which is equal to $\theta_{f}$ divided by $\theta_{y_{i}} K_{i}$ : The secant stiffness of each primary cycle under cyclic loading test; $+M_{i}$ : The positive peak moment of the $i$-th primary cycle; $-M_{i}$ : The negative peak moment of the $i$-th primary cycle; $+\theta_{i}$ : Rotation angle corresponding to $+M_{i ;}-\theta_{i}$ : Rotation angle corresponding to $-M_{i} ; \varepsilon_{\mathrm{eq}}$ Equivalent viscous damping ratio; $E_{\mathrm{d}}$ : Dissipated energy in a primary cycle; $E_{\mathrm{p}}$ : Available potential energy in a primary cycle.
}

\section{Acknowledgements}

Not applicable.

\section{Authors' contributions}

ZL and $\mathrm{MH}$ contributed to conceptualization, methodology, and investigation. WF was involved in data curation, investigation, software, and writingreview and editing. JO was involved in software and validation. FL contributed to experiment and validation. All authors read and approved the final manuscript.

\section{Funding}

The authors gratefully acknowledge the National Natural Science Foundation of China (Grant No. 51878476 and No. 52078371) and Shanghai Rising-Star Program (Grant No. 21QA1409300).

\section{Availability of data and materials}

The datasets used and analyzed during the current study are available from the corresponding author on reasonable request.

\section{Declarations}

Ethics approval and consent to participate

Not applicable.

\section{Consent for publication}

Not applicable.

\section{Competing interests}

The authors declare that they have no competing interests.

\section{Author details}

${ }^{1}$ Department of Structural Engineering, Tongji University, Shanghai 200092, People's Republic of China. ${ }^{2}$ Key Laboratory of Performance Evolution and Control for Engineering Structures of Ministry of Education, Tongji University, Shanghai 200092, People's Republic of China. ${ }^{3}$ China Southwest Architectural Design \& Res Inst C, Chengdu 610041, People's Republic of China.

Received: 30 August 2021 Accepted: 24 November 2021

Published online: 17 December 2021

\section{References}

1. Shu Z, Li Z, Yu XS, Zhang J, He MJ (2019) Rotational performance of glulam bolted joints: experimental investigation and analytical approach. Constr Build Mater 213:675-695

2. Moses DM, Prion HGL (2003) A three-dimensional model for bolted connections in wood. Can J Civ Eng 30(3):555-567

3. Wang $M Q$, Song XB, Gu XL, Zhang YF, Luo L (2014) Study on rotational behavior of bolted glulam beam-to-column connections with slotted-in steel plates. J Build Struc 35(9):141-150

4. Leijten AJM, Brandon D (2013) Advances in moment transfering dvw reinforced timber connections - analysis and experimental verification, Part 1. Constr Build Mater 43:614-622

5. Larsen HJ, Jensen JL (2000) Influence of semi-rigidity of joints on the behaviour of timber structures. Prog Struct Eng Mat 2(3):267-277

6. Blass HJ, Bejtka DI (2004) Reinforcements perpendicular to the grain using self-tapping screws. WCTE 2004-8th world conference on timber engineering. Lahti, WCTE

7. Lam F, Gehloff M, Closen M (2010) Moment-resisting bolted timber connections. Proc Inst Civil Eng Struct Build 163(4):267-274

8. Gehloff M, Closen M, Lam F (2010) Reduced edge distances in bolted timber moment connections with perpendicular to grain reinforcements. WCTE 2010-11 th world conference on timber engineering. WCTE, Riva del Garda

9. He MJ, Liu HF (2015) Comparison of glulam post-to-beam connections reinforced by two different dowel-type fasteners. Constr Build Mater 99:99-108

10. Wang MQ, Song XB, Gu XL, Zhang YF, Luo L (2015) Rotational behavior of bolted beam-to-column connections with locally cross-laminated glulam. J Struct Eng 141(4):04014121

11. Sun XF, He MJ, Li Z (2020) Novel engineered wood and bamboo composites for structural applications: state-of-art of manufacturing technology and mechanical performance evaluation. Constr Build Mater 249:118751

12. Bouchair $A$, Racher P, Bocquet JF (2007) Analysis of dowelled timber to timber moment-resisting joints. Mater Struct 40(10):1127-1141

13. Haller P, Birk T, Offermann P, Cebulla H (2006) Fully fashioned biaxial weft knitted and stitch bonded textile reinforcements for wood connections. Compos Pt B Eng 37(4-5):278-285

14. Santos CL, Jesus AMP, Morais JJL, Fontoura BFC (2013) An experimental comparison of strengthening solutions for dowel-type wood connections. Constr Build Mater 46:114-127

15. Karagiannis V, Malaga-Chuquitaype C, Elghazouli AY (2017) Behaviour of hybrid timber beam-to-tubular steel column moment connections. Eng Struct 131:243-263 
16. Li Z, He MJ, Wang KL (2018) Hysteretic performance of self-centering glulam beam-to-column connections. J Struct Eng 144(5):04018031

17. Leijten AJM, Ruxton S, Prion H, Lam F (2006) Reversed-cyclic behavior of a novel heavy timber tube connection. J Struct Eng 132(8):1314-1319

18. Jung KH, Kitamori A, Komatsu K (2009) Development of a joint system using a compressed wooden fastener l: evaluation of pull-out and rotation performance for a column-sill joint. J Wood Sci 55(4):273-282

19. Jung KH, Kitamori A, Komatsu K (2010) Development of a joint system using a compressed wooden fastener II: evaluation of rotation performance for a column-beam joint. J Wood Sci 56(2):118-126

20. Araki Y, Endo T, Iwata M (2011) Feasibility of improved slotted bolted connection for timber moment frames. J Wood Sci 57(3):247-253

21. He MJ, Zhao Y, Ma RL (2016) Experimental investigation on lateral performance of pre-stressed tube bolted connection with high initial stiffness. Adv Struct Eng 19(5):762-776

22. Yeoh D, Fragiacomo M, De Franceschi M, Buchanan AH (2011) Experimental tests of notched and plate connectors for LVL-concrete composite beams. J Struct Eng 137(2):261-269

23. Fragiacomo M, Lukaszewska E (2013) Time-dependent behaviour of timber-concrete composite floors with prefabricated concrete slabs. Eng Struct 52(9):687-696

24. Bedon C, Fragiacomo M (2017) Three-dimensional modelling of notched connections for timber-concrete composite beams. Struct Eng Int 27(2):184-196

25. Smith I, Foliente G, Nguyen M, Syme M (2005) Capacities of dowel-type fastener joints in Australian pine. J Mater Civ Eng 17(6):664-675

26. Symons D, Persaud R, Stanislaus H (2010) Slip modulus of inclined screws in timber-concrete floors. Proc Inst Civil Eng Struct Build 163(4):245-255

27. Sebastian WM, Piazza M, Harvey T, Webster T (2018) Forward and Reverse shear transfer in beech LVL-concrete composites with singly inclined coach screw connectors. Eng Struct 175:231-244

28. Jiang YC, Hong W, Hu XM, Crocetti R, Wang L, Sun WM (2017) Early-age performance of lag screw shear connections for glulam-lightweight concrete composite beams. Constr Build Mater 151:36-42

29. Du H, Hu XM, Jiang YC, Wei CY, Hong W (2019) Loading carrying capacity of self-tapping lag screws for glulam-lightweight concrete composite beams. BioResources 14(1):166-179

30. Hassanieh A, Valipour HR, Bradford MA (2016) Experimental and analytical behaviour of steel-timber composite connections. Constr Build Mater 118:63-75

31. Hassanieh A, Valipour HR, Bradford MA (2016) Load-slip behaviour of steel-cross laminated timber (CLT) composite connections. J Constr Steel Res 122:110-121

32. Li Z, Wang XJ, He MJ (2020) Experimental and analytical investigations into lateral performance of cross laminated timber (CLT) shear walls with different construction methods. J Earthqu Eng. https://doi.org/10.1080/ 13632469.2020.1815609

33. Sun XF, He MJ, Li Z, Lam F (2019) Seismic performance assessment of conventional CLT shear wall structures and post-tensioned CLT shear wall structures. Eng Struct 196:109285

34. GB 50017-2017 (2017) Standard for design of steel structures. China's National Standard, Beijing

35. Porteous J, Kermani A (2007) Structural timber design to Eurocode 5. Blackwell, London

36. ASTM D1761-12 (2012) Standard test methods for mechanical fasteners in wood. Pennsylvania, ASTM

37. ASTM E2126-11 (2012) Standard test methods for cyclic (reversed) load test for shear resistance of vertical elements of the lateral for resisting systems for building. Pennsylvania, ASTM

38. Yu XS (2018) Mechanical properties on standardized beam-to-column joint of laminated Timber. Dissertation. Tongji University, Shanghai

39. EN 1995, Eurocode 5 (2008) Design of timber structure-Part 1-1. General common rules and rules for buildings. European Committee for Standardization, CEN, Brussels

40. Smith I, Asiz A, Snow M, Chui YH (2006) Possible Canadian/ISO approach to deriving design values from test data. International council for research and innovation in building and construction working commission W18 - timber structure. WCTE, Sweden

\section{Publisher's Note}

Springer Nature remains neutral with regard to jurisdictional claims in published maps and institutional affiliations.

\section{Submit your manuscript to a SpringerOpen ${ }^{\circ}$ journal and benefit from:}

- Convenient online submission

- Rigorous peer review

- Open access: articles freely available online

- High visibility within the field

- Retaining the copyright to your article

Submit your next manuscript at $\boldsymbol{\nabla}$ springeropen.com 